Research Article

\title{
Flexural Behavior of RC Slabs Strengthened in Flexure with Basalt Fabric-Reinforced Cementitious Matrix
}

\author{
Sugyu Lee, ${ }^{1}$ Kinam Hong $\mathbb{D}^{1},{ }^{1}$ Yeongmo Yeon, ${ }^{1}$ and Kyusan Jung ${ }^{2}$ \\ ${ }^{1}$ Department of Civil Engineering, Chungbuk National University, 1 Chungdae-ro, Seowon-Gu, Cheongju, Chungbuk 28644, \\ Republic of Korea \\ ${ }^{2}$ Structural Engineering Research Institute, Korea Institute of Civil Engineering and Building Technology, 283 Daehwa-dong, \\ Goyangdae-ro, Ilsanseo-gu, Goyang-si, Gyeonggi-do 10223, Republic of Korea \\ Correspondence should be addressed to Kinam Hong; hong@cbnu.ac.kr
}

Received 22 August 2017; Accepted 26 November 2017; Published 11 February 2018

Academic Editor: Doo-Yeol Yoo

Copyright (@) 2018 Sugyu Lee et al. This is an open access article distributed under the Creative Commons Attribution License, which permits unrestricted use, distribution, and reproduction in any medium, provided the original work is properly cited.

\begin{abstract}
This paper presents both experimental and analytical research results for predicting the flexural capacity of reinforced concrete (RC) slabs strengthened in flexure with basalt fabric-reinforced cementitious matrix (FRCM). A total of 13 specimens were fabricated to evaluate the flexural behavior of RC slabs strengthened with basalt FRCM composite and were tested under fourpoint loading. The fiber type, tensile reinforcement ratio, and the number of fabric layers were chosen as experimental variables. The maximum load of FRCM-strengthened specimens increased from $11.2 \%$ to $98.2 \%$ relative to the reference specimens. The energy ratio and ductility of the FRCM-strengthened specimens decreased with the higher amount of fabric and tensile reinforcement. The effective stress level of FRCM fabric can be accurately predicted by a bond strength of ACI 549 and Jung's model.
\end{abstract}

\section{Introduction}

Reinforced concrete structures experience degradation due to design errors, construction errors, aging, and increased loads caused by changes in usage [1]. These deteriorated structures can recover their load bearing capacity through strengthening $[2,3]$. Strengthening methods are largely divided into enlargement of concrete section, externally bonded reinforcement (EBR), and near-surface mounted reinforcement (NSMR) [4]. Particularly, the EBR method is easy to apply because reinforcing materials such as steel plate and fiber are adhered to the concrete surface by an epoxy resin and also exhibit excellent strengthening effect [5]. Steel plates were used mainly as the EBR strengthening material 20 to 30 years ago. However, it had been known that steel plates attached to the outside of concrete structures are vulnerable to corrosion and fire and greatly increase the weight of the structure [6]. Thus, at present, sheets or plates made up of carbon fiber-reinforced polymer (CFRP), glass fiber-reinforced polymer (GFRP), and aramid fiber-reinforced polymer (AFRP) are used as strengthening materials in replace of steel plates. The FRP strengthening material has a high strength-to-weight ratio and has excellent corrosion resistance, chemical resistance, and endothelial strength $[7,8]$. Despite these many advantages, FRP strengthening material attached to the exterior of the structure by the epoxy resin is prone to damage by fire and ultraviolet radiation [9]. Additionally, epoxy used as adhesive has the following limitations: (1) difficult to control quality in wet condition, difficult to harden at low temperatures in winter, and very low fire resistance due to the lower glass transition temperatures and (2) due to the epoxy resin matrix kept the moisture at interface between the concrete surface and the epoxy resin matrix, the strengthening material might be debonded from the concrete surface $[3,10]$.

Since inorganic cementitious matrix has a higher glass transition temperature than the organic epoxy resin, it is excellent in stability at high temperature, can be used under wet conditions due to hydration reaction, and also can 
prevent the fiber damage due to the ultraviolet ray [11]. In order to compensate the disadvantages of the epoxy resin, a fabric-reinforced cementitious matrix (FRCM) method, which is a strengthening method using the cementitious matrix as an adhesive, has been studied [4, 8-10, 12, 13]. Babaeidarabad et al. [12] conducted a bending test considering the number of polybenzoxazole (PBO) fabric layers and the concrete compressive strength as experimental variables. The experimental test results were compared with the flexural strengths predicted by ACI 549 [14]. The comparison results showed that the predicted flexural strengths were lower than the experimental values, but the criterion had an appropriate accuracy [12]. Ombres [7] performed a four-point bending test for FRCMstrengthened beams considering the tensile reinforcement ratio and the number of FRP fabric layers as experimental variables in order to analyze the flexural behavior, ultimate strength, deflection, ductility, and failure mode. Experimental test results showed that the ultimate strengths of strengthened specimens increased by $10 \%$ to $44 \%$ compared to the reference specimen. The specimen strengthened with one FRP fabric layer failed by flexural behavior, and the specimen with more than two FRP fabric layers failed due to FRP debonding at the midspan. In addition, the predicted value for maximum load is significantly different from the experimental test value when the specimen was destroyed by FRCM peeling [7]. D'Ambrisi et al. [11] conducted flexural tests on FRCM-strengthened beams considering the type of fiber, the number of fabric layers, and the fixing method as experimental variables. From the experimental results, it was confirmed that the $\mathrm{PBO}$ fabric is more efficient than the CFRP fabric in the FRCM method. Furthermore, the specimens strengthened with FRCM were destroyed due to the loss of reinforcing effect caused by peeling of the FCRM composite [11]. Azam and Soudki [15] conducted an experimental study to investigate the strengthening performance of beams strengthened in shear with the FRCM method. Threepoint loading tests were carried out on FRCM shearstrengthened beams considering the type of fibers and reinforcement as experimental variables. Experimental results showed that the ultimate load increase of $19 \%$ to $105 \%$ from the type of fibers and strengthening type has no significant effect on failure mode and failure load of the specimen [15]. Jung et al. [16] conducted flexural tests on FRCM-reinforced beams by varying the type of fabric and the number of fabric layers. Experimental results showed that FRCM-reinforced specimens increased by $131.7 \%$ to $219.8 \%$ compared to the reference specimen and all of FRCM-strengthened specimens were destroyed by FRCM composite peeling. Additionally, Jung et al. [16] suggested a bonding strength model for considering the bond-slip behavior between the BFRP fabric and the cementitious matrix on FRCM.

PBO fabric, CFRP fabric, and GFRP fabric were used as reinforcing materials in most studies regarding the FRCM composites [17, 18]. However, due to decomposition of epoxy matrix, the tensile strength of CFRP and GFRP at $600^{\circ} \mathrm{C}$ decreased to less than $60 \%$ of the strength measured at room temperature, and the tensile strength of $\mathrm{PBO}$ fabric at $500^{\circ} \mathrm{C}$ decreased to less than $40 \%$ of the strength measured at room temperature $[17,19]$. Therefore, even if the epoxy is replaced with a cementitious matrix, it should be considered that the sufficient fire resistance cannot be secured if these fabrics are used as strengthening materials. Unlike other fibers, basalt fiber is known to have more than $90 \%$ of the tensile strength measured at room temperature even at $600^{\circ} \mathrm{C}$ [3]. However, only few researchers have reported the application of the basalt fiber as a material of FRCM composites [3, 20, 21]. Therefore, this study reports the flexural performance of FRCMstrengthened beams with basalt fiber-reinforced polymer (BFRP) fabric. Moreover, the strength prediction model for FRCM-strengthened beams was examined for FRCMstrengthened slab structure.

\section{Experimental Program}

2.1. Test Specimens. A total of 13 specimens were fabricated to evaluate the flexural behavior of RC slabs strengthened with FRCM composite. The type of fibers, tensile reinforcement ratio, and the number of fabric layers were chosen as experimental variables. The specimens had a rectangular cross section of $400 \mathrm{~mm} \times 200 \mathrm{~mm}$, and their cover concrete depth was constantly $30 \mathrm{~mm}$. The total length and net span of the specimen were $3,400 \mathrm{~mm}$ and $3,000 \mathrm{~mm}$, respectively. Two deformed steel bars with nominal diameter of $10 \mathrm{~mm}$ were placed as compressive reinforcement in all specimens. Deformed steel bars with nominal diameter of $10 \mathrm{~mm}, 13 \mathrm{~mm}$, and $16 \mathrm{~mm}$ were utilized as the variable of tensile reinforcement in the specimens.

Also, in order to prevent the occurrence of shear failure before flexural failure, U-shaped stirrups with nominal diameter of $10 \mathrm{~mm}$ were placed at $200 \mathrm{~mm}$ intervals on the specimens. Specimen details are presented in Figure 1.

2.2. Materials. The specimens were fabricated by using ready-mixed concrete with the design strength of $30 \mathrm{MPa}$. In order to confirm the mechanical properties of concrete, nine cylinders of $\varnothing 100 \mathrm{~mm}$ were manufactured in accordance with ASTM C39/39M [22] at the time of concrete casting. The cylinders were cured under the same condition as the specimens. The average compressive strength of specimens was $33.8 \mathrm{MPa}$ at 28 days. The mixture properties of the concrete used are presented in Table 1 . Symbols in Table 1 are water-cement ratio $(W / C)$, sand percent of total aggregate by solid volume $(S / a)$, water $(W)$, cement $(C)$, sand $(S)$, gravel $(G)$, and water-reducing admixture (Ad).

Deformed steel bars with nominal diameters of $10 \mathrm{~mm}$, $13 \mathrm{~mm}$, and $16 \mathrm{~mm}$ were used in specimen fabrication. Their mechanical properties were determined in accordance with ASTM A370 [23], and the test results are shown in Table 2.

BFRP and CFRP fabrics were used in this study. The used CFRP fabric in this research was manufactured in Switzerland, consisting of carbon fiber in the warp direction and glass fiber in the weft direction. 


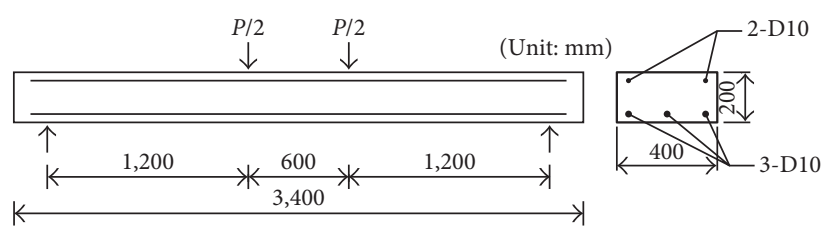

(a)

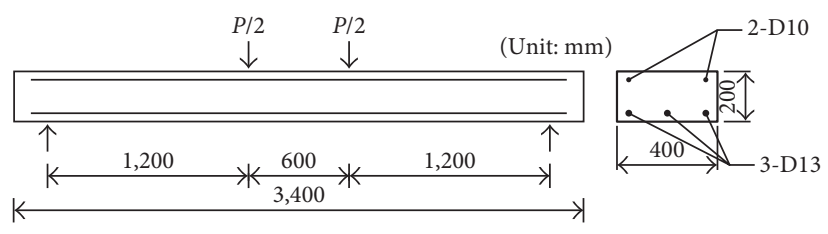

(b)

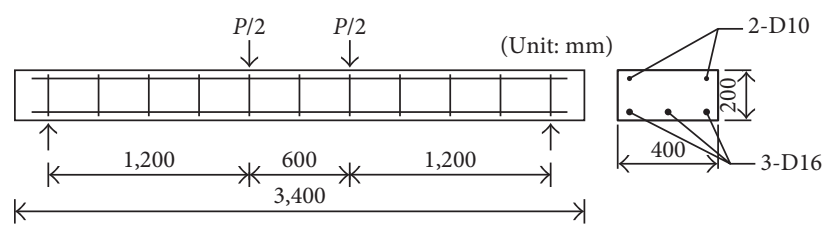

(c)

Figure 1: Details of test specimens. (a) R41. (b) R55. (c) R87.

TABle 1: Mixture properties of concrete.

\begin{tabular}{lcccccc}
\hline \multirow{2}{*}{$W / C(\%)$} & \multirow{2}{*}{$S / a(\%)$} & $W$ & $C$ & $S$ & $G$ & Ad \\
\hline 46.7 & 48.1 & 168 & 360 & 860 & 949 & 2.02 \\
\hline
\end{tabular}

The spacing of the carbon fiber strips and the glass fiber strips was $15 \mathrm{~mm}$ and $30 \mathrm{~mm}$, respectively. The BFRP fabric has excellent fire resistance performance compared to the CFRP fabric, while its tensile strength is $30 \%$ of CFRP strength. The fire resistance of the basalt fabric is 1.5 times greater than the fire resistance of the CFRP or GFRP fabric [24]. Thus, a direct tensile test as shown in Figure 2 was conducted as a preliminary experiment to determine the amount of BFRP fabrics having an equivalent to tensile strength of the CFRP fabric. Thus, as a preliminary test, direct tensile test as shown in Figure 2 was conducted to determine the required amount of BFRP fabrics with an equivalent to tensile strength of the CFRP fabric.

As a result, the thickness of the BFRP fabric with the same tensile strength as the CFRP fabric in the warp direction was determined to be 4.88 times the thickness of the CFRP fabric. The BFRP fabric consisted of basalt fiber in both warp and weft directions. Also, the spacing of warp and weft strips of BFRP fabric was $15 \mathrm{~mm}$ and $30 \mathrm{~mm}$, respectively. Table 3 and Figure 3 present the mechanical properties and shapes of the fabrics used as a strengthening material in this research.

Cementitious matrix used as binder consisted of silica sand, polypropylene fiber, cement, fly ash, and polymer powder. The compression test for the cementitious matrix was performed at the curing age of 28 days in accordance with ASRM C109/C109M [25]. Its compression strength was $46.3 \mathrm{MPa}$.

2.3. Experimental Variables. The experimental variables tested were tensile reinforcement ratio $(0.41 \%, 0.55 \%$, and $0.87 \%$ ), different strengthening materials (CFRP fabric and BFRP fabric), and different number of fabric layers (1-layer, 2-layers, and 3-layers). Test parameter details are given in Table 4 . The nomenclature of the specimens follows the experimental variables used. In this research, unstrengthened specimen was fabricated as a reference specimen.

A single specimen strengthened with the CFRP fabric was tested to compare its behavior to a behavior of reinforced concrete slab with the BFRP fabric with the tensile reinforcement ratio of $0.41 \%$. The comparison of the global behavior between the slabs reinforced with the CFRP fabric and BFRP fabric presents feasibility of the BFRP fabric as the reinforcement material.

The tensile reinforcement ratio of the specimen was labeled using a letter abbreviation and an Arabic number. The first letter, $\mathrm{R}$, represents the tensile reinforcement ratio. The following Arabic number, 41, 55, or 87, represents the tensile reinforcement ratios of $0.41 \%, 0.55 \%$, and $0.87 \%$, respectively. Next to the symbol “-”, the letter, N, C, and B represent the nonstrengthened CFRP fabric, and BFRP fabric, respectively. The following Arabic numbers, 1, 2, and 3 , represent the 1-layer, 2-layers, and 3-layers of fabric, respectively. For example, "R55-B3" denotes a strengthen specimen with the tensile reinforcement ratio of $0.55 \%$ and 3-layers of BFRP fabric. 
TABLE 2: Material properties of the used steel.

\begin{tabular}{lccc}
\hline Nominal diameter $(\mathrm{mm})$ & Yield stress $(\mathrm{MPa})$ & Ultimate stress $(\mathrm{MPa})$ & Modulus of elasticity $(\mathrm{GPa})$ \\
\hline 10 & 487 & 621 & 204 \\
13 & 469 & 671 & 199 \\
16 & 449 & 622 & 194 \\
\hline
\end{tabular}

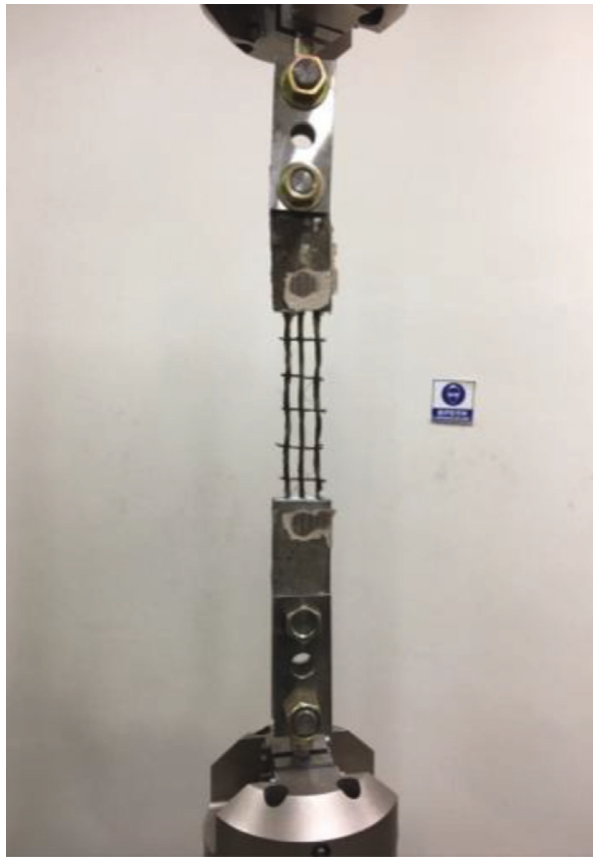

Figure 2: Direct tensile test of FRP fabric.

2.4. Specimen Preparation. Prior to strengthening the concrete slab by FRCM composite, the concrete specimens were rotated $180^{\circ}$ so that the strengthening surface of specimens would be the upper surface. The laitance on their strengthening surface was removed using sandblaster and washed with high pressure water.

FRCM strengthening was proceeded as follows: (a) apply the cementitious matrix on the strengthening surface with a thickness of $5 \mathrm{~mm}$ by using a shotcrete machine; (b) place the FRP fabric on the matrix; and (c) apply the cementitious matrix with a thickness of $5 \mathrm{~mm}$ on FRP fabric. For the specimens with 2-layers and 3-layers of BFRP fabric, the above procedure was repeated two and three times, respectively. The flexural test was conducted after 28 days of strengthening procedure, so that the cement matrix would have enough time to develop its strength.

2.5. Test Setup. The specimens were loaded with a $2,000 \mathrm{kN}$ capacity actuator at a stroke speed of $3 \mathrm{~mm} / \mathrm{min}$. The test was carried out under a four-point loading system, and the distance between loading points was $600 \mathrm{~mm}$. Two linear variable differential transformers (LVDTs) were installed on the lower surface of the specimen to measure the deflection of the specimen at midspan. Additionally, the strain values of the concrete, tensile steel bar, compression steel bar, and fabric of FRCM composite were measured by the strain gages installed at the midspan section of specimens. The measured strain values were recorded at a frequency of 1 second by a data logger.

\section{Test Result and Discussion}

3.1. Failure Mode. Figure 4 shows the deformed shape of the representative specimens after test. Reference specimens R41$\mathrm{NN}, \mathrm{R} 55-\mathrm{NN}$, and R87-NN were failed by the yielding of tensile rebar followed by the concrete crushing of the compression zone. All of the FRCM-strengthened specimens had fabric slippage in FRCM composite after the maximum load and were ultimately failed by the tensile fracture of the fabric followed by the concrete crushing of the compression zone. Additionally, it should be noted that the peeling failure of the FRCM composite did not occur in any specimen. Figure 5 shows the crack pattern at the midspan of R55-B1, R55-B2, and R55-B3 specimens. It can be seen from Figure 5 that the flexural cracks were developed at regular intervals in the midspan and propagated toward the compression zone. Furthermore, the FRCM composite was broken with a concrete hammer after the end of the test to investigate the BFRP fabric if the fabric was damaged. It was confirmed that about $60 \%$ of the basalt fabric was broken.

3.2. Load-Displacement Curves. Table 5 and Figure 6 show the summary of test results and the comparison of loaddisplacement curves for all specimens, respectively. Figure 6(a) shows the comparison of the load-displacement curves of R41-C1 and R41-B1 specimens strengthened with 1 layer of CFRP fabric and BFRP fabric, respectively. They show very similar flexural behavior before yielding of steel rebar. After yielding of steel rebar, the load of R41-C1 strengthened with CFRP fabric with relatively high elastic modulus increased more rapidly than that of R41-B1. However, the maximum loads of R41-C1 and R41-B1 were increased by $30.7 \%$ and $40.9 \%$, respectively, compared with that of R41-NN. This is because the CFRP fabric has about 8 times higher elastic modulus than the BFRP fabric, resulting in the slip of R41-C1 earlier than R41-B1.

Figure 6(b) shows a comparison of the loaddisplacement curves of the specimens strengthened with the 1, 2, and 3 layers of BFRP fabric, respectively, all of which had the same tensile reinforcement ratio of $0.41 \%$. As the number of fabric layers increased, the initial crack load 


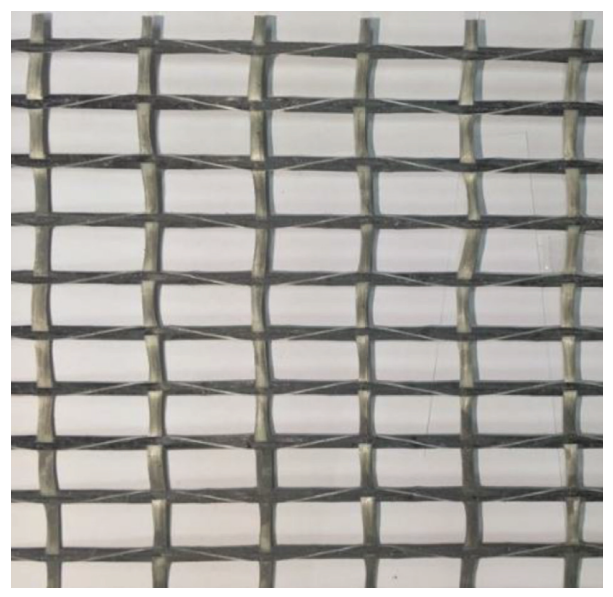

(a)

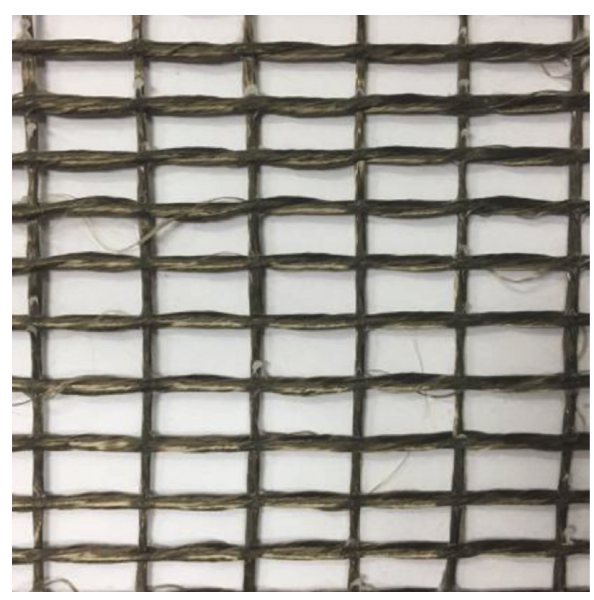

(b)

FIgURE 3: FRP fabrics. (a) CFRP fabric. (b) BFRP fabric.

TABLE 3: Material properties of FRP fabric.

\begin{tabular}{lcccc}
\hline Fabric & Nominal thickness $\left(\mathrm{mm}^{2} / \mathrm{mm}\right)$ & Ultimate tensile strain & Ultimate tensile stress $(\mathrm{MPa})$ & Modulus of elasticity $(\mathrm{GPa})$ \\
\hline BFRP fabric & 0.522 & 0.023 & 274.85 & 11.84 \\
CFRP fabric & 0.107 & 0.014 & 1314.68 & 94.85 \\
\hline
\end{tabular}

TABLE 4: Test parameter details.

\begin{tabular}{lccc}
\hline Specimen & Tensile reinforcement ratio (\%) & Strengthening material & Number of fabric layers \\
\hline R41-NN & 0.41 & None & 0 \\
R41-C1 & 0.41 & CFRP & 1 \\
R41-B1 & 0.41 & BFRP & 1 \\
R41-B2 & 0.41 & BFRP & 2 \\
R41-B3 & 0.41 & BFRP & 3 \\
\hline R55-NN & 0.55 & None & 0 \\
R55-B1 & 0.55 & BFRP & 1 \\
R55-B2 & 0.55 & BFRP & 2 \\
R55-B3 & 0.55 & BFRP & 3 \\
R87-NN & 0.87 & None & 0 \\
R87-B1 & 0.87 & BFRP & 1 \\
R87-B2 & 0.87 & BFRP & 2 \\
R87-B3 & 0.87 & BFRP & 3 \\
\hline
\end{tabular}

increased. The yielding load of R41-B1, R41-B2, and R41-B3 increased to $27.1 \%, 25.3 \%$, and $43.6 \%$, respectively, compared with that of R41-NN. The slope of the curve increased steeply in proportion to the number of fabric layers after yielding of steel rebar. The maximum loads of R41-B1, R41-B2, and R41-B3 were increased to $40.9 \%, 52.0 \%$, and $98.2 \%$, respectively, compared with R41-NN.

Figure 6(c) shows a comparison of the load-displacement curves of the specimens strengthened with the 1,2, and 3 layers of BFRP fabric, all of which had the same tensile reinforcement ratio of $0.55 \%$. As with specimens with a tensile reinforcement ratio of $0.41 \%$, the initial crack loads and yielding loads of specimens with a tensile reinforcement ratio of $0.55 \%$ increased in proportion to the number of fabric layers. In addition, the flexural rigidity of the specimens was not improved significantly before yielding of steel rebar but improved in proportion to the number of fabric layer after yielding of steel rebar. The maximum load of R51-B1, R51-B2, and R51-B3 increased to $17.1 \%, 40.2 \%$, and $62.8 \%$, respectively, compared with that of R51-NN. 


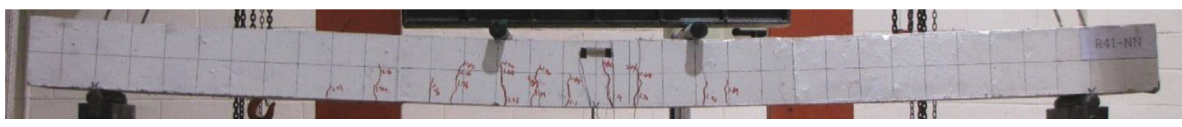

(a)

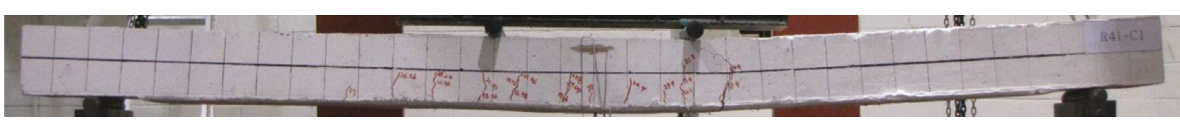

(b)

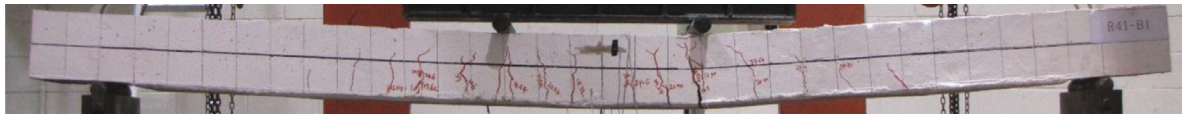

(c)

FIGURE 4: Deformed shapes of specimens after testing. (a) R41-NN. (b) R41-C1. (c) R41-B1.

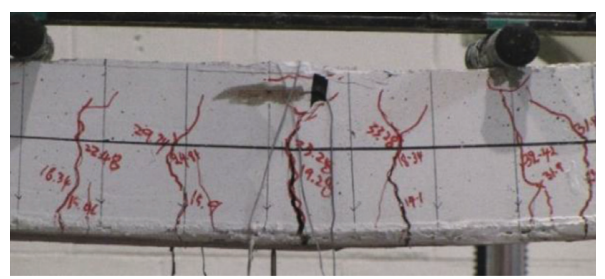

(a)

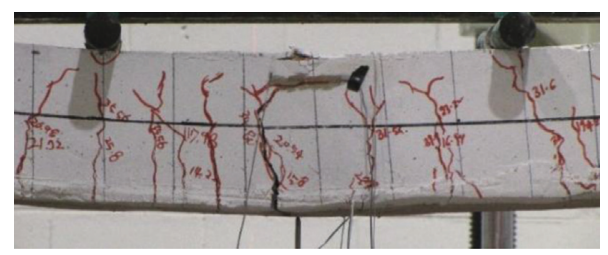

(b)

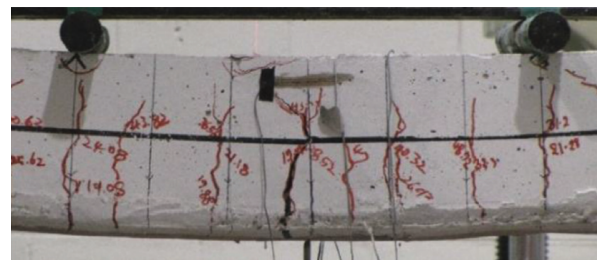

(c)

Figure 5: Crack pattern at midspan. (a) R55-B1. (b) R55-B2. (c) R55-B3.

Figure 6(d) shows a comparison of the load-displacement curves of the specimens strengthened with the 1,2 , and 3 layers of BFRP fabric, all of which had the same tensile reinforcement ratio of $0.87 \%$. As with specimens with other tensile reinforcement ratios, the flexural rigidity of the specimens was not improved significantly before yielding of steel rebar, but improved in proportion to the number of fabric layer after yielding of steel rebar. The maximum load of R87-B1, R87-B2, and R87-B3 increased to $11.2 \%, 29.0 \%$, and $48.8 \%$, respectively, compared with that of R51-NN. It should also be noted that the increasing ratio of maximum load decreases as the tensile reinforcement ratio increases.
3.3. Load-Strain Curves. Figure 7 shows the strain distribution along the depth at a midspan cross section of representative specimens. The strains of concrete, tensile reinforcement, and FRP fabric were evaluated at representative load stages. It can be observed from Figure 7 that the strain distribution is linear at the low load level, while it becomes nonlinear and the slippage between FRP fabric and the cementitious matrix occurs after $60 \%$ of the maximum load. From $80 \%$ of the ultimate load stages, the strains of the FRP fabric were reduced compared to the strains of steel, which might be because the cementitious matrix was broken and slippage occurred between FRP fabric and cementitious 
TABLE 5: Summary of test results.

\begin{tabular}{lccc}
\hline Specimens & Yielding load $(\mathrm{kN})$ & Maximum load $(\mathrm{kN})$ & Load increase over reference $(\%)$ \\
\hline R41-NN & 28.94 & 34.90 & - \\
R41-C1 & 39.70 & 45.60 & 30.7 \\
R41-B1 & 36.82 & 49.16 & 40.9 \\
R41-B2 & 36.26 & 53.06 & 52.0 \\
R41-B3 & 41.36 & 69.16 & 98.2 \\
\hline R55-NN & 43.28 & 50.42 & - \\
R55-B1 & 47.50 & 59.06 & 17.1 \\
R55-B2 & 49.14 & 70.70 & 40.2 \\
R55-B3 & 54.22 & 82.08 & 62.8 \\
\hline R87-NN & 64.84 & 70.72 & - \\
R87-B1 & 66.08 & 78.66 & 11.2 \\
R87-B2 & 74.56 & 91.20 & 29.0 \\
R87-B3 & 75.54 & 105.24 & 48.8 \\
\hline
\end{tabular}

material. Consequently, it should be noted that the strain distribution at low load level can be assumed to be linear, but it cannot be considered as linear at the high load level due to the slippage between FRP fabric and cementitious matrix. Thus, the slippage between FRP fabric and cementitious material needs to be taken into account in order to accurately predict the flexural performance of FRCMstrengthened slabs.

3.4. Ductility. Ductility is generally expressed as the ratio of the deflection at the time of steel yielding to the ultimate deflection. In this research, the fracture mode of the specimen was determined by the ductility index " $\mu$ " proposed by Jeong [26] shown in Figure 8. The ductility index is expressed in (1):

$$
\begin{aligned}
\mu & =\frac{1}{2}\left(\frac{E_{\mathrm{tot}}}{E_{\mathrm{el}}}+1\right), \\
E_{\mathrm{tot}} & =E_{\mathrm{in}}+E_{\mathrm{el}},
\end{aligned}
$$

where $\mu$ is the ductility index, $E_{\text {tot }}$ is the total energy which is calculated as the area under the load-displacement curve up to the failure load, $E_{\mathrm{el}}$ is the elastic energy which is a part of the total energy, and $E_{\text {in }}$ is the inelastic energy, as illustrated in Figure 8.

Based on the ductility index proposed by Jeong [26], Grace et al. [27] developed failure modes depending on the energy ratio. The energy ratio $\left(E_{\mathrm{in}} / E_{\text {tot }}\right)$ is classified into a range of $75 \%$ or more, $70 \%$ to $75 \%$, or $70 \%$ or less and is defined as the ductile, semibrittle, or brittle failure mode, respectively. Table 6 shows the failure mode evaluation results of each specimen defined by this criterion. For nonreinforced specimens, the total energy and elastic energy increase while the energy ratio decreases as the tensile steel reinforcement ratio increases. The energy ratios of the R41-NN, R55-NN, and R87-NN were 83.5\%, 76.5\%, and 69.3\%, which are defined as the ductile mode, ductile mode, and brittle mode, respectively.

The ductile fracture mode absorbs a large amount of energy before fracture, which was shown in R41-NN, R41-B1, and R55-NN. With increase of the tensile reinforcement ratio, the failure mode was changed from the ductile to the brittle mode. The brittle fracture was shown in the R41-C1, R41-B3, R55-B2, R55-B3, R87-B1, R87-B2, and R87-B3. All of those mentioned specimens failed by the debonding of the FRP fabric with the broken cementitious matrix.

Compared to the R41-NN, the total energy of the R41-C1 specimen with a layer of CFRP fabric was reduced by $28.2 \%$, while the elastic energy was increased by $74.4 \%$. The energy ratio of $\mathrm{R} 41-\mathrm{C} 1$ was $60.3 \%$, confirming that the failure mode of this specimen was brittle failure. However, for the R41-B1 specimen with a layer of BFRP fabric, both the total energy and the elastic energy increased compared with those of R41$\mathrm{NN}$, and its energy ratio was $76.0 \%$, indicating ductile failure.

For the specimens with the tensile reinforcement ratio of $0.41 \%$, the energy ratio decreased with the increase of the number of BFRP fabric layers. The energy ratios of the R41-B1, R41-B2, and R41-B3 were 76.0\%, 70.9\%, and 63.6\%, which are defined as the ductile mode, semiductile mode, and brittle mode, respectively.

For the specimens with the tensile reinforcement ratio of $0.55 \%$, the energy ratio and the total energy decreased with the increase of the number of BFRP fabric layers. The energy ratios of the $\mathrm{R} 55-\mathrm{B} 1, \mathrm{R} 55-\mathrm{B} 2$, and $\mathrm{R} 55-\mathrm{B} 3$ were $74.0 \%$, $67.0 \%$, and $65.1 \%$, which are defined as the ductile mode, brittle mode, and brittle mode, respectively.

For the specimens with the tensile reinforcement ratio of $0.87 \%$, the energy ratio and the total energy decreased with the increase of the number of BFRP fabric layers. The energy ratios of the $\mathrm{R} 87-\mathrm{B} 1, \mathrm{R} 87-\mathrm{B} 2$, and $\mathrm{R} 87-\mathrm{B} 3$ were $67.4 \%, 61.2 \%$, and $56.5 \%$, which are defined as brittle mode.

Also, it can be seen that the ductility of the FRCMstrengthened specimens decreased with the higher amount of fabric and the higher tensile reinforcement ratio. 


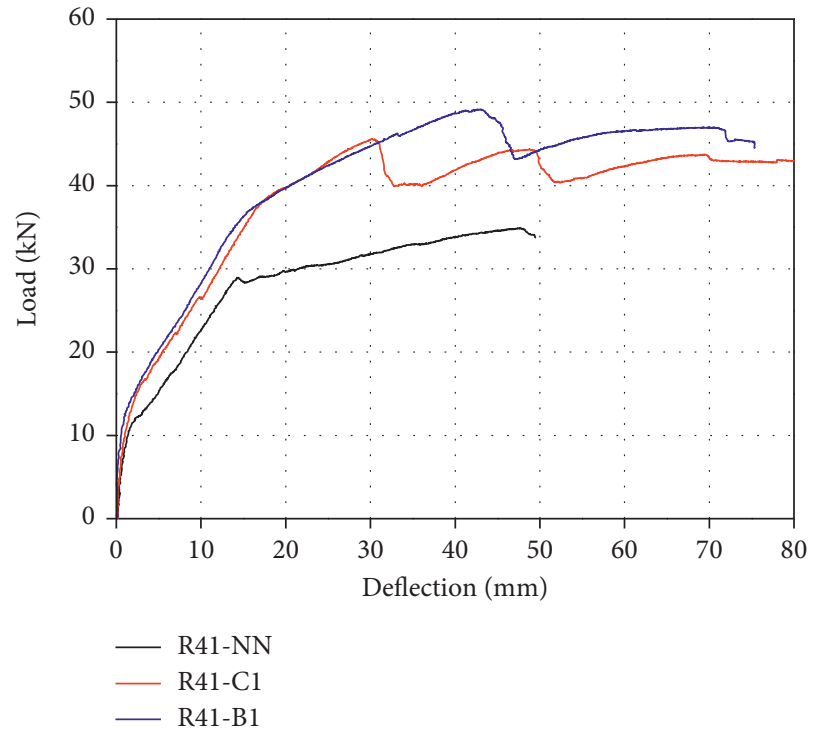

(a)

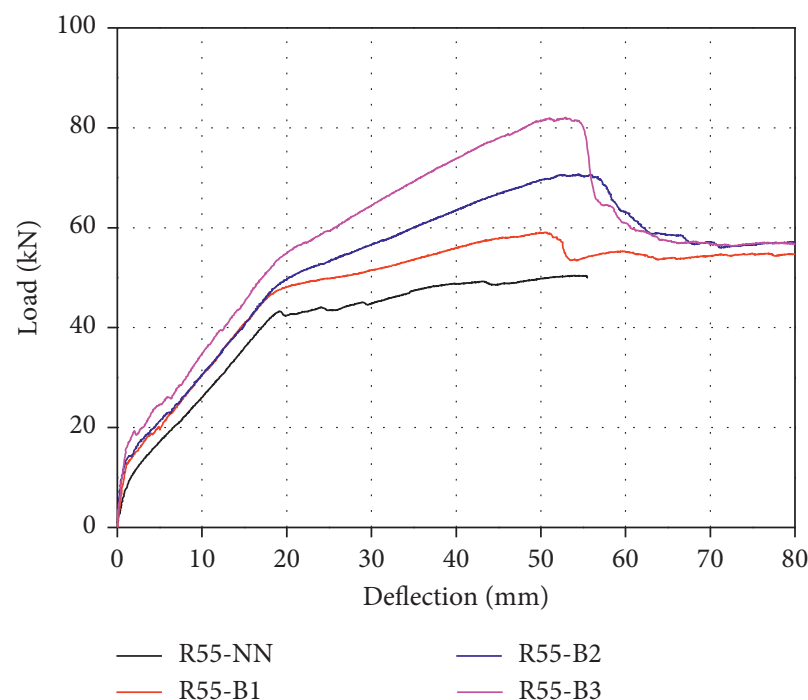

(c)

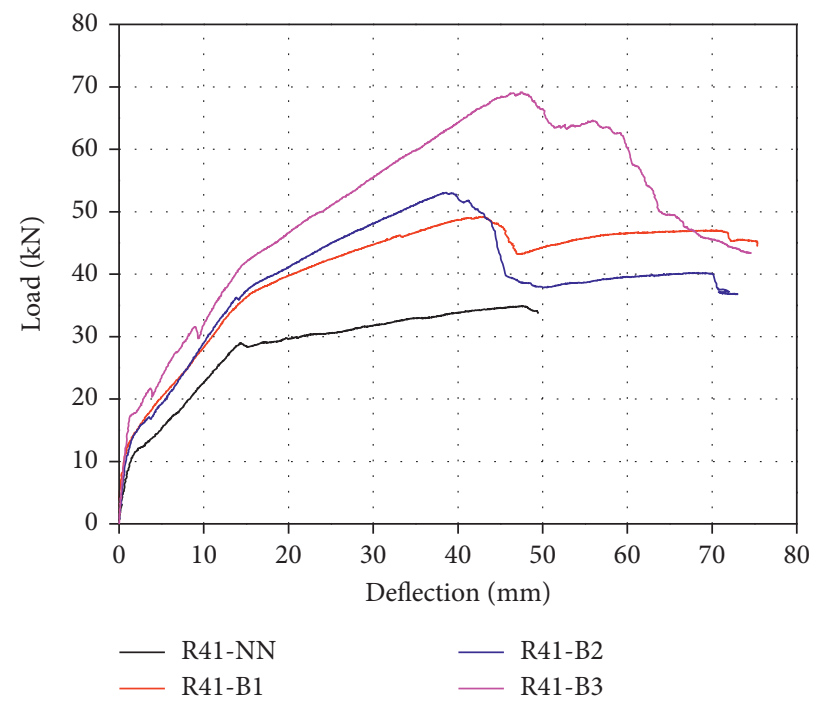

(b)

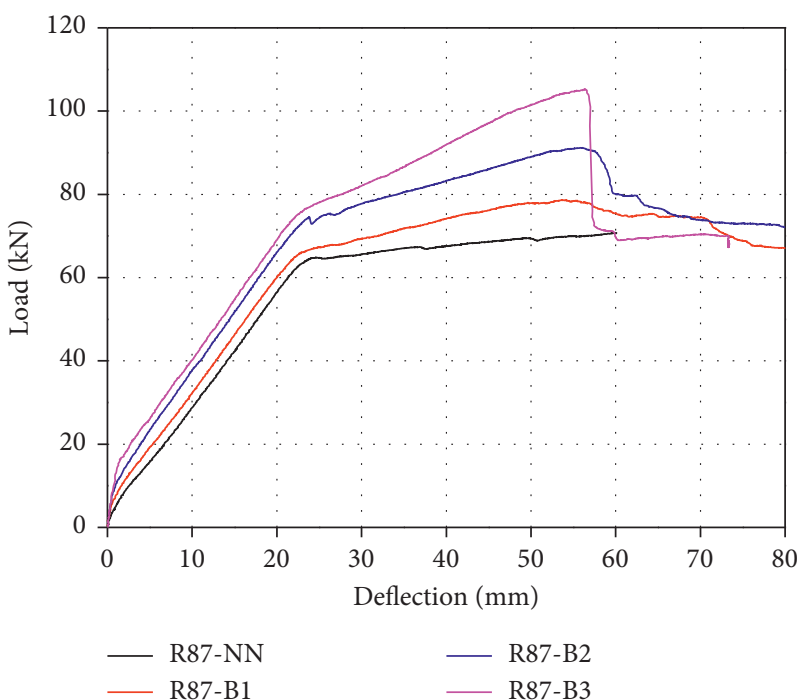

(d)

Figure 6: Comparison of load-deflection curves. (a) Specimens with CFRP and BFRP fabric. (b) Specimens with the tensile reinforcement ratio of $41 \%$. (c) Specimens with the tensile reinforcement ratio of 55\%. (d) Specimens with the tensile reinforcement ratio of $87 \%$

\section{Numerical Approach}

\subsection{Effective Tensile Stress Level of FRCM Fabric}

4.1.1. ACI 549. In ACI 549 [14], the effective tensile strain level in the FRCM fabric attained at failure, $\varepsilon_{\mathrm{fe}}$, is limited to the design tensile strain of the FRCM fabric, $\varepsilon_{\mathrm{fd}}$, as defined in

$$
\varepsilon_{\mathrm{fe}}=\varepsilon_{\mathrm{fd}} \leq 0.012 .
$$

Also, the effective tensile stress level in the FRCM fabric attained at failure, $f_{\mathrm{fe}}$, in the FRCM composite is calculated in accordance with

$$
f_{\mathrm{fe}}=E_{f} \varepsilon_{\mathrm{fe}},
$$

where $E_{f}$ is the elastic modulus of FRCM fabric.

4.1.2. Jung Model. Jung et al. [16] proposed the FRCM bond strength model with regard to both the slippage and the debonding phenomenon of the FRCM composite by (5), based on the FRCM research performed by D'Ambrishi et al. [18] and the model proposed by Teng et al. [28]. The effective tensile stress level in the FRCM fabric at failure can be computed by the following equations: 


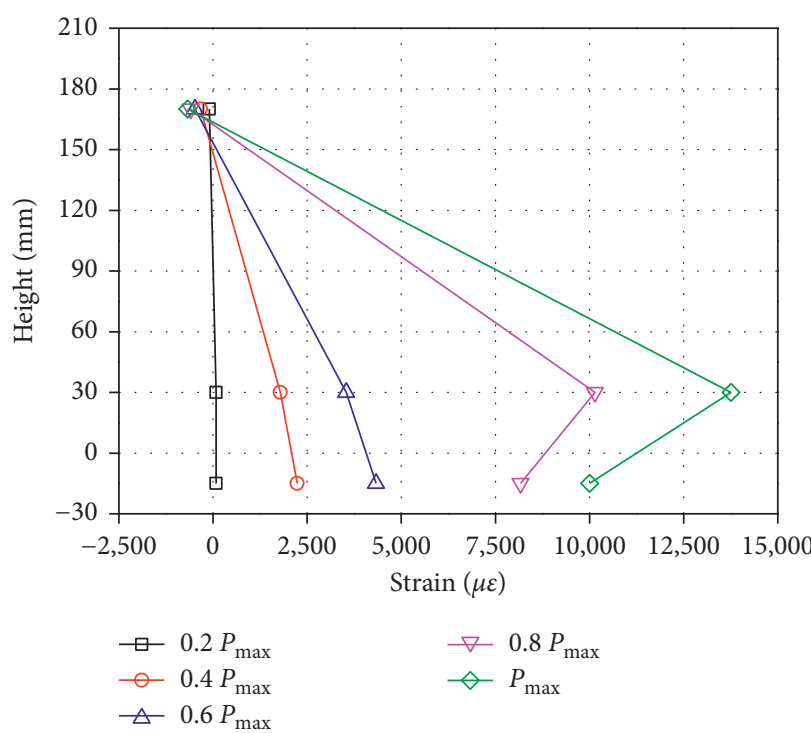

(a)

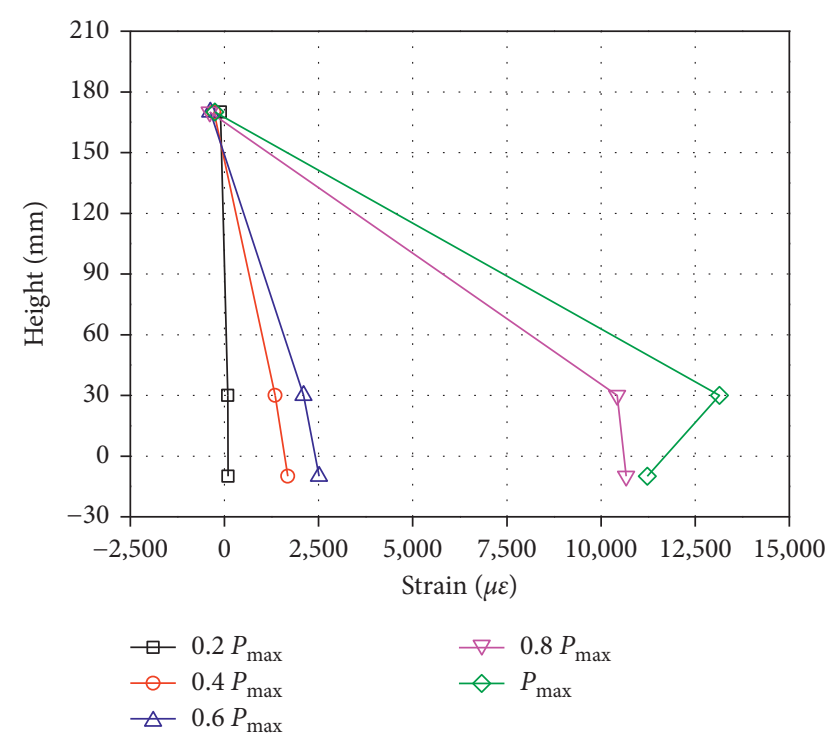

(b)

FIgURE 7: Load-strain relation. (a) R55-B1. (b) R55-B3.

$$
\begin{aligned}
& f_{\mathrm{fe}}=\alpha \beta_{F} \beta_{L} \sqrt{\frac{E_{F} \sqrt{f_{c}^{\prime}}}{t_{1} \sqrt{n}}}, \\
& \beta_{F}=\sqrt{\frac{2-b_{F} / b_{c}}{1+b_{F} / b_{c}}}, \\
& \beta_{L}=\left\{\begin{array}{l}
1, \quad \text { if } \quad L \geq L_{e} \\
\sin \frac{\pi L}{2 L_{e}}, \quad \text { if } \quad L<L_{e},
\end{array}\right. \\
& L_{e}=\sqrt{\frac{E_{F} t_{F}}{f_{c}^{\prime}},}
\end{aligned}
$$

where $b_{F}$ is the width of the FRCM fabric, $b_{c}$ is the width of the specimen, $L$ is the bond length, $L_{e}$ is the effective bond length, $E_{F}$ is the elastic modulus of the FRCM fabric, $t_{F}$ is the total thickness of the FRCM fabric, $f_{c}^{\prime}$ is the cylinder compressive strength for concrete, and $\alpha$ is the reduction factor and given as 0.727 for FRCM by Jung et al. [16]. Additionally, $t_{1}$ is the nominal thickness of a layer of the FRCM fabric and $n$ is the number of fabric layers.

4.2. Nominal Flexural Strength. Nominal flexural strength was calculated by using ACI 318 [13] and ACI 549 [14]. First, the neutral axis depth, $c_{u}$, satisfying the internal force equilibrium expressed by (6), (7) was determined by the trial and error method:

$$
T_{f}+T_{s}=C
$$

where

$$
\begin{aligned}
T_{s} & =A_{s} f_{y}, \\
T_{f} & =n A_{f} f_{\mathrm{fe}}, \\
C & =\alpha_{1} f_{c}^{\prime} \beta_{1} c_{u} b, \\
\alpha_{1}\left(c_{u}\right) & =\frac{3 \varepsilon_{c}^{\prime} \varepsilon_{c}\left(c_{u}\right)-\left[\varepsilon_{c}\left(c_{u}\right)\right]^{2}}{3 \beta_{1}\left(c_{u}\right) \varepsilon_{c}^{\prime 2}}, \\
\beta_{1}\left(c_{u}\right) & =\frac{4 \varepsilon_{c}^{\prime}-\varepsilon_{c}\left(c_{u}\right)}{6 \varepsilon_{c}^{\prime}-2 \varepsilon_{c}\left(c_{u}\right)}, \\
\varepsilon_{c}^{\prime} & =\frac{1.7 f_{c}^{\prime}}{E_{c}}, \\
E_{c} & =4700 \sqrt{f_{c}^{\prime}}, \\
\varepsilon_{\mathrm{fe}} & =\frac{f_{\mathrm{fe}}}{E_{f}}, \\
\varepsilon_{c} & =\frac{c_{u}}{h-c_{u}} \varepsilon_{\mathrm{fe}},
\end{aligned}
$$

where $T_{s}, T_{f}, C, A_{s}, A_{f}, f_{y}, n, \alpha_{1}, \beta_{1}, \varepsilon_{c}^{\prime}, \varepsilon_{c}, E_{c}, f_{\mathrm{fe}}, \varepsilon_{\mathrm{fe}}$, and $E_{f}$ are the tensile force provided by tensile rebar, tensile force provided by the FRCM composite, compressive force provided by concrete, area of tensile steel rebar, area of the FRP fabric, yielding strength of steel rebar, number of FRP fabrics, concrete stress block factor, compressive strain attained in the maximum compressive strength of unconfined 


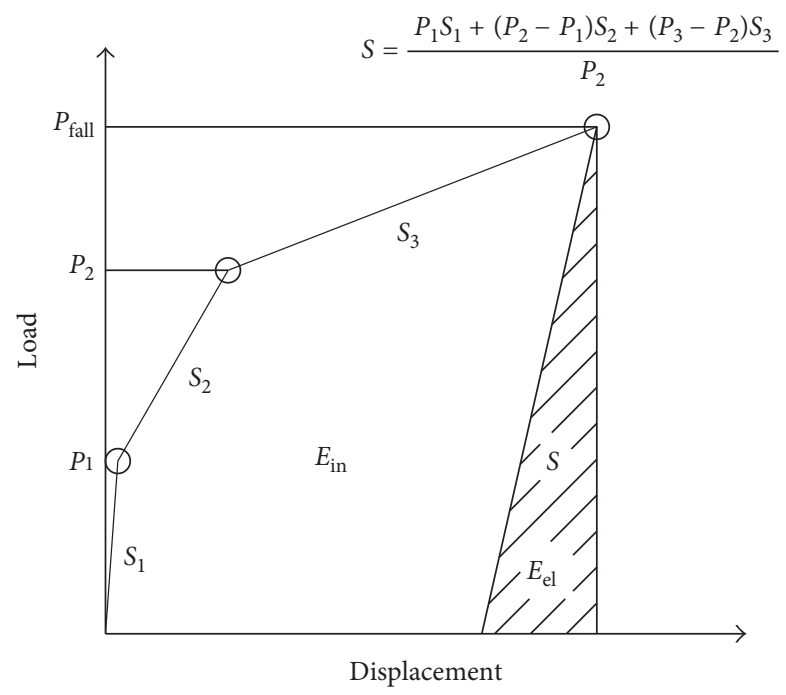

Figure 8: Definition of ductility index [17].

TABLE 6: Results of ductility evaluation.

\begin{tabular}{|c|c|c|c|c|c|c|}
\hline Specimen & $E_{\mathrm{el}}(\mathrm{J})$ & $E_{\text {in }}(\mathrm{J})$ & $E_{\text {tot }}(\mathrm{J})$ & $\mu_{\text {energy }}$ & Energy ratio (\%) & Failure mode \\
\hline R41-NN & 217 & 1100 & 1317 & 3.53 & 83.5 & Ductile \\
\hline $\mathrm{R} 41-\mathrm{C} 1$ & 379 & 575 & 954 & 1.76 & 60.3 & Brittle \\
\hline R41-B1 & 372 & 1175 & 1547 & 3.53 & 76.0 & Ductile \\
\hline $\mathrm{R} 41-\mathrm{B} 2$ & 413 & 1006 & 1419 & 2.22 & 70.9 & Semiductile \\
\hline R41-B3 & 808 & 1409 & 2217 & 1.87 & 63.6 & Brittle \\
\hline R55-NN & 506 & 1641 & 2146 & 2.62 & 76.5 & Ductile \\
\hline R55-B1 & 581 & 1653 & 2234 & 2.42 & 74.0 & Semiductile \\
\hline R55-B2 & 880 & 1786 & 2665 & 2.01 & 67.0 & Brittle \\
\hline R55-B3 & 1027 & 1912 & 2939 & 1.93 & 65.1 & Brittle \\
\hline R87-NN & 995 & 2250 & 3245 & 2.13 & 69.3 & Semiductile \\
\hline R87-B1 & 1005 & 2078 & 3082 & 2.03 & 67.4 & Brittle \\
\hline R87-B2 & 1414 & 2235 & 3649 & 1.79 & 61.2 & Brittle \\
\hline $\mathrm{R} 87-\mathrm{B} 3$ & 1754 & 2275 & 4029 & 1.65 & 56.5 & Brittle \\
\hline
\end{tabular}

concrete, strain in the concrete, elastic modulus of concrete, strength of the FRCM composite, strain in the FRCM composite, and elastic modulus of the FRCM composite.

The nominal flexural strength, $M_{n}$, can be calculated in accordance with the following equations:

$$
\begin{aligned}
& M_{n}=M_{s}+M_{f}, \\
& M_{s}=A_{s} f_{y}\left(d-\frac{\beta_{1} c_{u}}{2}\right), \\
& M_{f}=A_{f} b f_{\mathrm{fe}}\left(h-\frac{\beta_{1} c_{u}}{2}\right),
\end{aligned}
$$

where $d$ and $h$ are the effective depth and height of specimen cross section, respectively.

4.3. Prediction of Nominal Flexural Strength. Table 7 shows the comparisons of nominal flexural strength predicted by
ACI 549 [14] and the Jung model [16]. The ratios of the test result to the predicted flexural strength by ACI 549 were ranged from 0.97 to 1.14 . The mean and standard deviation of the ratios of the test result to the prediction value by ACI 549 were 1.08 and 0.05 , respectively. The ratios of the test result to the predicted value by Jung model were ranged from 0.94 to 1.14 . The mean and standard deviation of the ratios of the test result to the predicted value by the Jung model were 1.05 and 0.06 , respectively. Consequently, the Jung model predicts the effective stress level more accurately than ACI 549. However, it can be noted that both ACI 549 and the Jung model predict the effective stress level of the FRCM fabric with the sufficient accuracy to be applied for the FRCM strengthening design of the $\mathrm{RC}$ slab.

\section{Conclusion}

The following conclusions are drawn from the results: 
TABLE 7: Comparison of nominal flexural strength.

\begin{tabular}{|c|c|c|c|c|c|}
\hline \multirow{2}{*}{ Specimen } & \multicolumn{3}{|c|}{ Nominal flexural strength } & \multirow{2}{*}{ Test/ACI 549} & \multirow{2}{*}{ Test/Jung model } \\
\hline & Test $(\mathrm{kN})$ & ACI $549(\mathrm{kN})$ & Jung model $(\mathrm{kN})$ & & \\
\hline R41-B1 & 29.50 & 27.33 & 29.18 & 1.08 & 1.01 \\
\hline $\mathrm{R} 41-\mathrm{B} 2$ & 31.84 & 32.69 & 33.94 & 0.97 & 0.94 \\
\hline R41-B3 & 41.50 & 38.00 & 38.08 & 1.09 & 1.09 \\
\hline $\mathrm{R} 55-\mathrm{B} 1$ & 35.44 & 32.97 & 34.80 & 1.07 & 1.02 \\
\hline R55-B2 & 42.42 & 38.25 & 39.48 & 1.11 & 1.07 \\
\hline R55-B3 & 49.25 & 43.47 & 43.55 & 1.13 & 1.13 \\
\hline R87-B1 & 47.20 & 45.39 & 46.94 & 1.04 & 1.01 \\
\hline R87-B2 & 54.72 & 50.44 & 51.52 & 1.08 & 1.06 \\
\hline R87-B3 & 63.14 & 55.37 & 55.43 & 1.14 & 1.14 \\
\hline & & & & Mean: 1.08, SD: 0.05 & Mean: 1.05, SD: 0.06 \\
\hline
\end{tabular}

(1) All of the FRCM-strengthened specimens had fabric slippage in FRCM composite after the maximum load and were ultimately destroyed by the tensile fracture of the fabric followed by the concrete crushing of the compression zone.

(2) The initial crack loads and yielding loads of specimens with three tensile reinforcement ratio of $0.41 \%$, $0.55 \%$, and $0.87 \%$ showed increasing trend in proportion to the number of fabric layers. Also, the maximum loads of FRCM-strengthened specimens increase from $11.2 \%$ to $98.2 \%$ relative to the reference specimens. Additionally, it should be noted that the increasing ratio of maximum load over the reference specimen decreases as the tensile reinforcement ratio increases.

(3) The strain distribution of the FRCM-strengthened specimen is linear at the low load level, while it becomes nonlinear after $60 \%$ of maximum load, resulting from the slippage between FRP fabric and the cementitious matrix. Thus, the slippage between FRP fabric and cementitious material needs to be considered in order to accurately predict the flexural performance of the FRCM-strengthened slabs.

(4) The energy ratio and ductility of the FRCMstrengthened specimens decreased with the higher amount of fabric and the higher tensile reinforcement. With the higher amount of fabric, the fracture mode was changed from ductile failure to brittle failure.

(5) The Jung model predicts the effective stress level more accurately than ACI 549 . However, it can be noted that both ACI 549 and the Jung model predict the effective stress level of the FRCM fabric with sufficient accuracy to be applied for FRCM strengthening design of the RC slab.

\section{Conflicts of Interest}

The authors declare no conflicts of interest.

\section{Acknowledgments}

This work was supported by the Korea Science and Engineering Foundation (KOSEF) grant funded by the Korea government (MOST) (no. 2015R1D1A1A01057453).

\section{References}

[1] K. Kovler and V. Chernov, "Types of damage in concrete structures," in Failure, Distress and Repair of Concrete Structures, pp. 32-56, Woodhead Publishing Limited, Cambridge, UK, 2009.

[2] G. Loreto, L. Leardini, D. Arboleda, and A. Nanni, "Performance of RC slab-type elements strengthened with fabricreinforced cementitious-matrix composites," Journal of Composites for Construction, vol. 18, no. 3, 2014.

[3] H. M. Elsanadedy, T. H. Almusallam, S. H. Alsayed, and Y. A. Al-Salloum, "Flexural strengthening of RC beams using textile reinforced mortar-experimental and numerical study," Composite Structures, vol. 97, pp. 40-55, 2013.

[4] S. W. Kim, Experimental Study on Bond Flexural Behavior of RC Members Using CFRP-Bar NSM System, Ph.D. thesis, pp. 1-4, Yeungnam University, Gyeongsan, Republic of Korea, 2015.

[5] H. J. Kim, Failure Behavior of Reinforced Concrete Beams with Flexural Strengthened by Steel Plates, Ph.D. thesis, pp. 17-22, Chonnam University, Gwangju, Republic of Korea, 2005.

[6] J. Y. Park, Behavior Characteristics and Strengthening Design of Reinforced Concrete Beam Strengthened with Carbon Fiber Reinforced Polymer Plate, Ph.D. thesis, pp. 1-3, Chungbuk University, Cheongju, Republic of Korea, 2003.

[7] L. Ombres, "Flexural analysis of reinforced concrete beams strengthened with a cement based high strength composite material," Composite Structures, vol. 94, no. 1, pp. 143-155, 2011.

[8] H. H. Lee and E. S. Koo, "A study on the strength and the deformation capacity of RC beams strengthened with aramid fiber sheet," Journal of the Korea Concrete Institute, vol. 10, pp. 151-158, 1998.

[9] T. C. Triantafillou and C. G. Papanicolau, "Shear strengthening of reinforced concrete members with textile reinforced mortar (TRM)," Materials and Structures, vol. 39, no. 1, pp. 93-103, 2006. 
[10] H. Ko, S. Matthys, A. Palmieria, and Y. Sato, "Development of simplified bond stress-slip model for bonded FRP-concrete interfaces," Construction and Building Materials, vol. 68, pp. 142-157, 2014.

[11] A. D'Ambrisi and F. Focacci, "Flexural strengthening of RC beams with cement-based composites," Journal of Composites for Construction, vol. 15, no. 5, pp. 707-720, 2011.

[12] S. Babaeidarabad, G. Loreto, and A. Nanni, "Flexural strengthening of RC beams with an externally bonded fabricreinforced cementitious matrix," Journal of Composites for Construction, vol. 18, no. 5, 2014.

[13] American Concrete Institute (ACI), Building Code Requirements for Reinforced Concrete (ACI 318), American Concrete Institute, Farmington Hills, MI, USA, 2011.

[14] American Concrete Institute (ACI), Design and Construction Guide of Externally Bonded FRCM System for Concrete and Masonry Repair and Strengthening (ACI 549), American Concrete Institute, Farmington Hills, MI, USA, 2013.

[15] R. Azam and K. Soudki, "FRCM strengthening of shearcritical RC beams," Journal of Composites for Construction, vol. 18, no. 5, 2014.

[16] K. Jung, K. Hong, S. Han, J. Park, and J. Kim, "Prediction of flexural capacity of RC beams strengthened in flexure with FRP fabric and cementitious matrix," International Journal of Polymer Science, vol. 2015, Article ID 868541, 11 pages, 2015.

[17] T. Kuroki, Y. Tanaka, T. Hokudoh, and K. Yabuki, "Heat resistance properties of poly (p-phenylene-2,6-benzobisoxazole) fiber," Journal of Applied Polymer Science, vol. 65, no. 5, pp. 1031-1036, 1997.

[18] A. D'Ambrisi, L. Feo, and F. Focacci, "Experimental analysis on bond between PBO-FRCM strengthening materials and concrete," Composites Part B: Engineering, vol. 44, no. 1, pp. 524-532, 2013.

[19] G. P. Lignola, C. Caggegi, F. Ceroni et al., "Performance assessment of basalt FRCM for retrofit applications on masonry," Composites Part B: Engineering, vol. 128, pp. 1-18, 2017.

[20] J. Sim, C. Park, and D. Y. Moom, "Characteristics of basalt fiber as a strengthening material for concrete structures," Composites Part B: Engineering, vol. 36, no. 6-7, pp. 504-512, 2005.

[21] Q. Liu, M. T. Shaw, R. S. Parnas, and A. M. McDonnell, "Investigation of basalt fiber composite mechanical properties for applications in transportation," Polymer Composites, vol. 27, no. 1, pp. 41-48, 2006.

[22] ASTM International, Standard Test Method for Compressive Strength of Cylindrical Concrete Specimens (ASTM C39/C39M), ASTM International, West Conshohocken, PA, USA, 2013.

[23] ASTM International, Standard Test Method and Definitions for Mechanical Testing of Steel Products (ASTM A370), ASTM International, West Conshohocken, PA, USA, 2013.

[24] V. Dhand, G. Mittal, K. Y. Rhee, S. J. Park, and D. Hui, "A short review on basalt fiber reinforced polymer composites," Composites Part B: Engineering, vol. 73, pp. 166-180, 2015.

[25] ASTM International, Standard Test Method for Compressive Strength of Hydraulic Cement Mortars (ASTM C109/C109M), ASTM International, West Conshohocken, PA, USA, 2013.

[26] S. M. Jeong, Evaluation of Ductility in Prestressed Concrete Beams Using Fiber Reinforced Plastic Tendons, Ph.D. thesis, University of Michigan, Ann Arbor, MI, USA, 1994.

[27] N. F. Grace, A. K. Soliman, G. Abdel-Sayed, and K. R. Saleh, "Behavior and ductility of simple and continuous FRP reinforced beams," Journal of Composites for Construction, vol. 2, no. 4, pp. 186-194, 1998.
[28] J. G. Teng, S. Y. smith, J. Yao, and J. F. Chen, "Intermediate crack-induced debonding in RC beams and slabs," Journal of Construction and Building Materials, vol. 17, no. 6-7, pp. 447-462, 2003. 


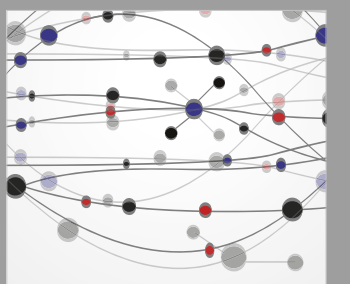

The Scientific World Journal
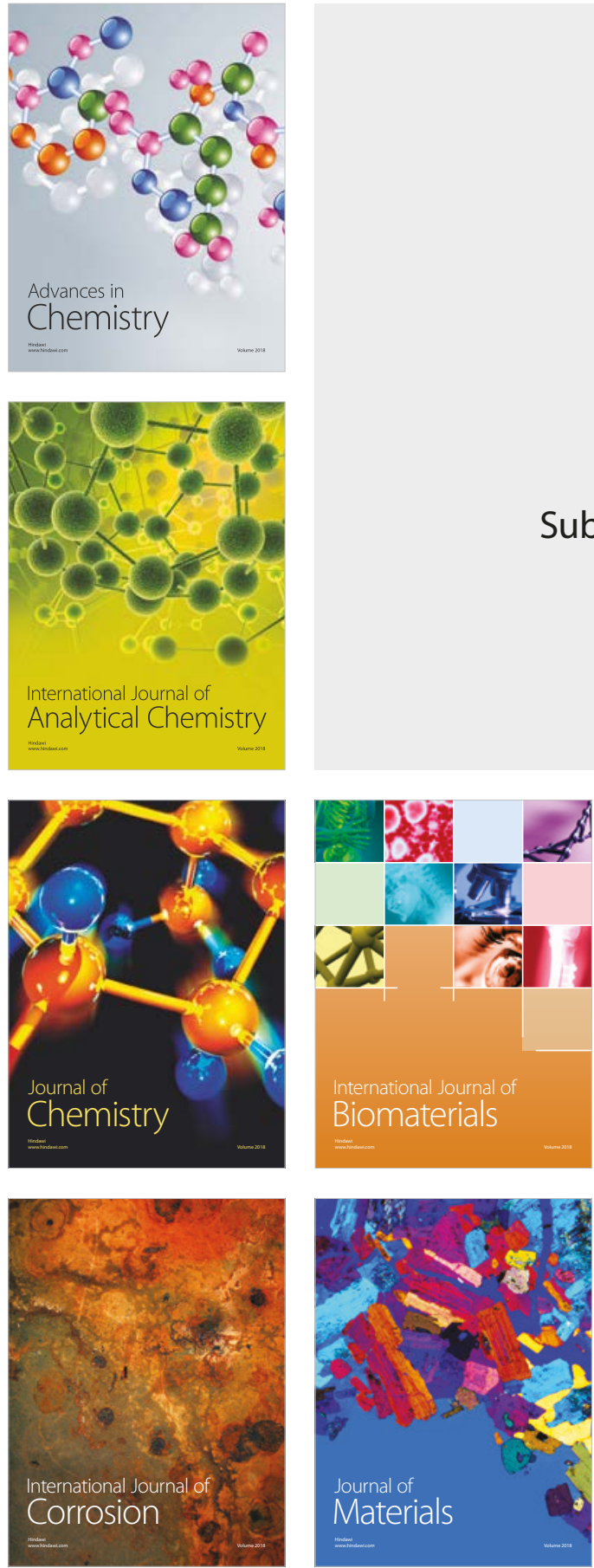

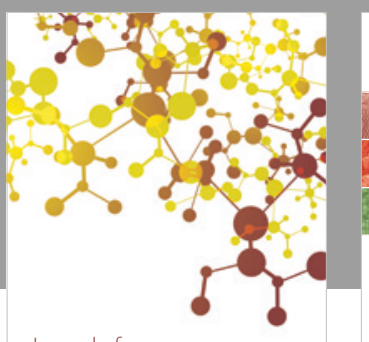

Journal of

Applied Chemistry
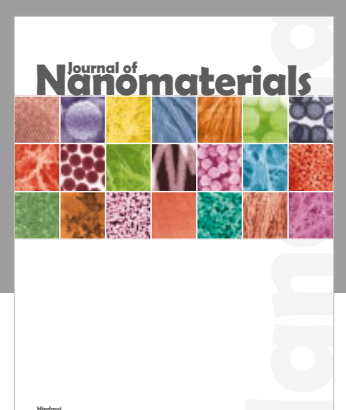

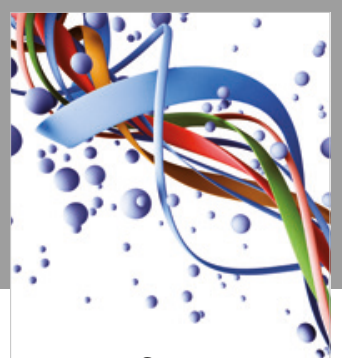

Scientifica

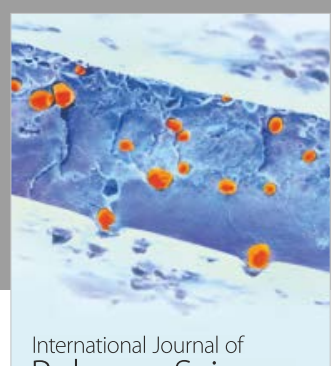

Polymer Science

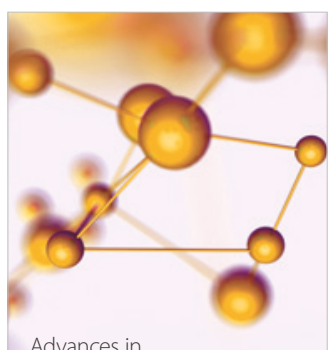

Physical Chemistry
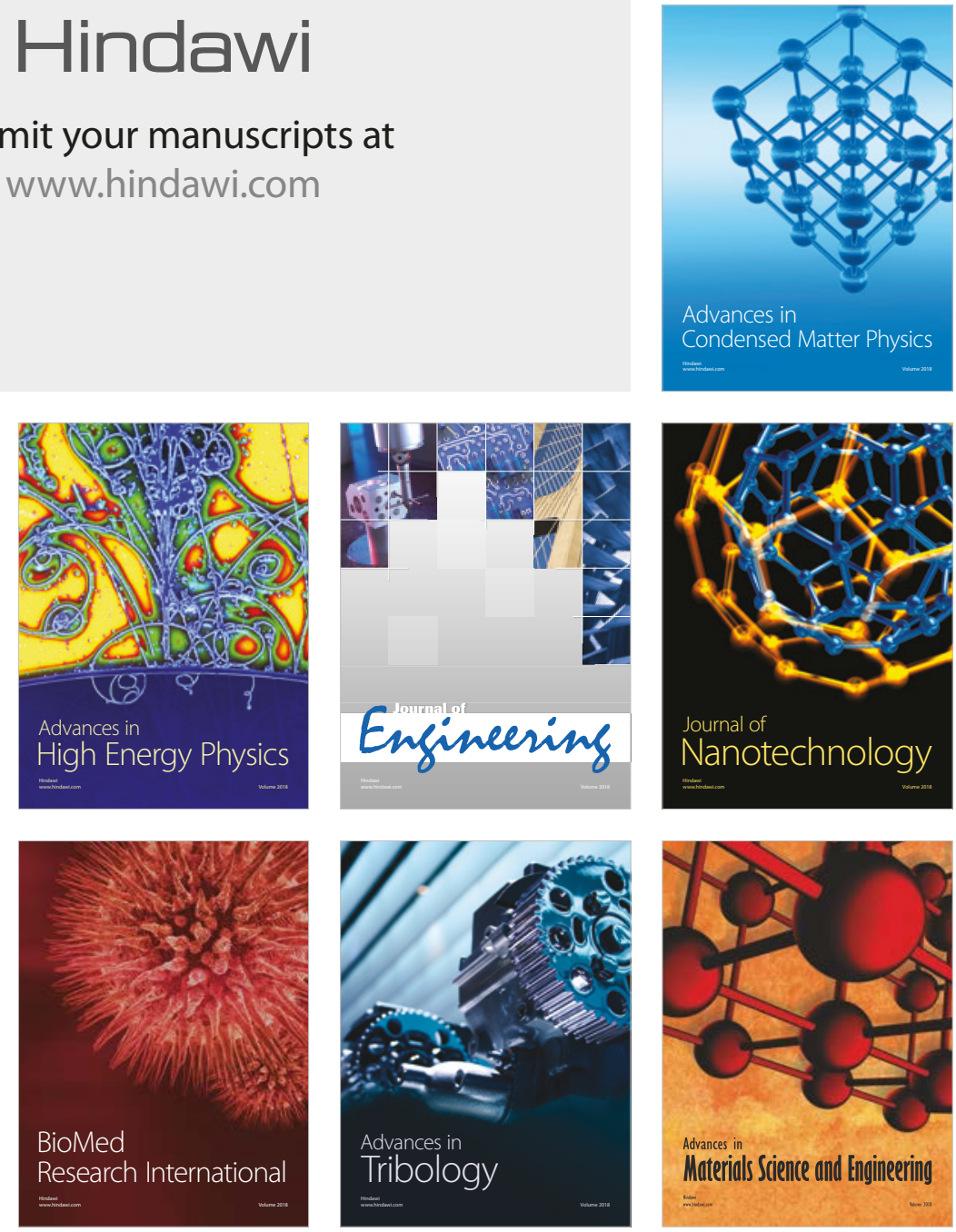